\title{
Global pedigree and national imperative: Hong Kong universities' response to China's grand strategies
}

\author{
William Yat Wai Lo ${ }^{1} \cdot$ Jack T. Lee $^{2} \cdot$ Dana Abdrasheva $^{1}$ \\ Accepted: 23 August 2021 / Published online: 1 September 2021 \\ (C) The Author(s) 2021
}

\begin{abstract}
Literature offers a theoretical framework exemplifying the inherent tensions between "becoming Chinese" and "remaining global" in the evolution of the international status of Hong Kong. Adopting this framework, this paper examines the global position of Hong Kong's higher education through an investigation of universities' participation in China's Belt and Road Initiative and Greater Bay Area development plan. Specifically, drawing on data from interviews about universities' engagement with the two Chinese grand strategies, the paper discusses university leaders and academics' experience and perception of Hong Kong's global status against a policy context that foregrounds a deeper integration with the Chinese national development. This discussion offers a theoretical dialogue that reveals different but overlapping scenarios for the future of Hong Kong's higher education and sheds light on the link between the changing geopolitical contexts and international higher education.
\end{abstract}

Keywords Internationalization · Hong Kong · China · Belt and Road Initiative · Greater Bay Area

\section{Introduction}

Since the handover of sovereignty from Britain to China, Hong Kong's policymakers have intensified efforts at redefining the city's identity in a post-colonial context. A crucial dimension of this redefining process involves maintaining Hong Kong's global status on the one hand and making the city an integral part of China on the other. One reason that the city needs to highlight its global status is that Hong Kong, as a Special Administrative Region (HKSAR) of China, has to compete with other Chinese cities to maintain its competitive edge in both global and national contexts. Global connectivity then is considered a competitive

William Yat Wai Lo

willlo@eduhk.hk

1 Department of International Education, The Education University of Hong Kong, 10 Lo Ping Road, Tai Po, New Territories, Hong Kong, China

2 Moray House School of Education and Sport, University of Edinburgh, Edinburgh EH8 8BJ, UK 
advantage of Hong Kong over its rivals. However, this intercity competition not only juxtaposes each city's characteristics and connectivity to the global economy, but it also exposes each city's connectivity to the Chinese national economic system, given the country's growing role in the global economic order (Han and Paul 2020) and technological innovations (Xie et al. 2014). Indeed, Hong Kong's economy has become increasingly dependent on Mainland China's development over the last two decades. Consequently, Hong Kong has undergone economic and political restructuring, which makes the city gradually embedded in Chinese national development. This study foregrounds Hong Kong's participation in two Chinese grand strategies: the Belt and Road Initiative (BRI) and the Greater Bay Area (GBA) development plan.

Both the BRI and the GBA plan outline China's key national development strategies. Announced in 2013, the BRI is a comprehensive undertaking viewed as the centerpiece of Chinese foreign policy under President Xi Jinping. Its original goal was to strengthen connectivity by building up infrastructure and establishing a network of key cities along the historical Silk Road. However, the BRI has quickly grown beyond a project of hard infrastructure to include the development of soft platforms to promote policy exchange, financial integration, free trade, and people-to-people bonds. Under this broader scope, higher education (HE) is expected to play a role in strengthening people-to-people connectivity through academic exchanges and cooperation. A tangible example of the Chinese government's commitment to higher education cooperation under the BRI is its provision of 10,000 scholarships a year to students who come from countries along the belt and road (State Council 2015).

The GBA plan first appeared in China's 13th Five-Year Plan in 2016. It aims to promote cross-border collaboration and integration among Hong Kong, Macau, and nine cities in the Guangdong Province of southern China. It also serves as a way to combine the strengths of the cities in the Pearl River Delta to support China's "going global" strategy, which is promoted by the BRI (Hui et al. 2020; Ren et al. 2020). Emphasizing innovation and technology, the initiative intends to take forward cooperation in various selected policy areas that would ultimately attain synergistic socio-economic development in the GBA. As education is one of the selected policy areas, universities in the region are encouraged to collaborate in research, student exchange, and the provision of education programs (Constitutional and Mainland Affairs Bureau (CMAB) 2018).

Hong Kong actively participates in both initiatives. Given its global connectivity, Hong Kong's policymakers identify the city as a "super-connector" that can utilize its international networks to help Mainland China "go global" in various domains through the BRI (Belt and Road Office (BRO) 2017). In the GBA plan, the Hong Kong Government highlights the city's role as an international financial, transportation, trade center, and aviation hub, which can facilitate China's further opening up, thereby serving the country's needs (Constitutional and Mainland Affairs Bureau (CMAB) 2018). Chief Executive Carrie Lam (2017) of the HKSAR further proclaims that "what the country needs, what Hong Kong is good at" (para. 58). This statement vividly describes Hong Kong's global positioning in relation to China's national aspirations. This agenda for becoming more deeply integrated into China's national development, as Chiu and Lui (2009) argue, is caused by the threat of being marginalized by the rapid development of other Chinese cities. Based on this argument, Hong Kong's global dimension is intertwined with China's national development and "going global" projects. As Chiu and Lui (2009) note: 
Given the galloping pace and momentum of China's economic growth and development, Hong Kong has been re-embedded in the national economic project of a globalizing China. (p. 160)

However, they go on to emphasize that the city needs to strike "a balance between being global and being Chinese by building an institutional structure" that would fit both sides (Chiu and Lui 2009, p. 162). This delicate balance between "becoming Chinese" and "remaining global" generates tensions through ideological differences, the anxieties over being marginalized in interurban competition, and the eagerness to capture the opportunities brought about by the rise of China (Chan 2019). The tenuous nature of this balance with its historical, cultural, and political dimensions confronts Hong Kong's $\mathrm{HE}$ as it navigates a complex future.

Our paper examines these tensions on Hong Kong's positioning through a critical study of its universities' engagements with the BRI and the GBA plan. With the ideas of building people-to-people bonds and promoting innovation and technology development at the heart of these initiatives, universities have become important sites for both the exchange of people and the cross-border research collaborations that operationalize these grand plans. Bringing together insights from different theorizations on the global status of Hong Kong and its HE, we examine Hong Kong HE's response to the two key national projects and the perspectives of its senior university leaders. We demonstrate that the imperative of leaning toward both East and West features prominently in Hong Kong HE's global aspirations despite the growing demands for integration with China's national development.

\section{Theorizing the global position of Hong Kong's HE}

Hong Kong's policymakers have emphasized the connection between the city's global status and China's national development. Academic literature constructs this account as an identification of Hong Kong as "a Chinese global city" (Chiu and Lui 2009) that puts the strategic development of the city within the national ambit of Mainland China.

Echoing this nationally oriented approach in its analysis of the global role of Hong Kong's $\mathrm{HE}$, some research on international HE considers this national imperative of Hong Kong's positioning a kind of normative force that directs the city's strategy for developing an education hub. As Knight (2013) explains, though Hong Kong intends to become a regional education hub, the evolution of its HE is mainly characterized by attracting large numbers of students from Mainland China and relatively few from the rest of the world. Thus, she points out that Hong Kong is an education gateway to China rather than a supranational regional education hub. Likewise, Lee (2014) questions the sustainability of this gateway model, as "many Hong Kong residents feel increasingly agitated by the influx of Mainland Chinese and the influence of the Chinese government" (p. 821). Nevertheless, this self-positioning of Hong Kong is rationalized by the nationally oriented perspective from which the education hub strategy primarily aims to develop the city into "a bridge for the international mobility of Mainland Chinese students" (Lo 2015, p. 64). This theoretical explanation emphasizes a national perspective on Hong Kong's contribution to internationalization of HE in Mainland China. It is evident from the official report, which stresses that the Hong Kong HE sector needs to serve the demand from the Mainland and contribute to national development (University Grants Committee (UGC). 2010). 
Focusing on intercity competition and collaboration, some literature further notes that the connection between Hong Kong's positioning and China's national development essentially involves Beijing's coordination. According to Shen (2010), such an idea of emphasizing national coordination rests on an assumption that the Chinese central government takes a coordinating role to mediate the competition among Chinese cities and even cities outside the country in order to prevent Hong Kong from being marginalized. This assumption partly explains Hong Kong's relentless efforts to maintain its global ties while leaving the central government to mediate competition from other Chinese cities. The emphasis on national coordination also underpins research on cross-border research collaboration between Hong Kong and Shenzhen. For example, Wang and her associates (2021) indicate that the growing linkages between the two cities in science and technology are materialized by close collaboration among universities from the two cities, institutionalized by the GBA framework and prioritized "not only by governments in both cities but also by the provincial and central governments" (p. 2). They use Qianhai, a special district in Shenzhen designated by the Chinese central government for facilitating "the joint development of financial industries by major financial entities from the two cities" (p. 4) to illustrate the coordinating role played by Beijing. In a similar vein, Kang and Jiang (2020) describe how Hong Kong and Shenzhen's HE sectors can strengthen talent flows and academic exchange by establishing cooperative endeavors within the GBA framework, thereby accelerating the sub-national regional integration and enhancing the international competitiveness of the HE sectors in the region. While they deny that there is "an over-simplistic division of labor between cities," they believe that the HE sectors of the two cities can "benefit from mutually complementary and advanced intercity collaboration and development" (p. 226).

In sum, the nationally oriented approach offers an effective theoretical lens through which to examine the positioning of post-handover Hong Kong and its HE in relation to the Chinese national development, as it acknowledges the changing economic and political contexts after 1997. This emphasis on the changing socio-political situation is especially important, as we witnessed a rapid upsurge of social tensions and conflicts in the territory in the last few years.

However, there is a counter-theory that stresses Hong Kong's historically based global ties and its status as "a global frontier" (Duara 2016) or "a borderland" (Marginson 2021). According to this internationally shaped approach, the global position of Hong Kong is defined by its political and cultural proximity to both China and the Western world. The political proximity (or ambiguity) refers to the situation where two opposing ideological systems, socialist and capitalist, could interact in Hong Kong during the Cold War. Hong Kong is seen as a cultural frontier that bridges diverse civilizations. For example, a group of Confucianists who were in exile took the city as a place for preserving and evolving Confucianism after 1949. With this frontier identity, Hong Kong exhibits a high degree of autonomy, openness, indeterminacy, and ambiguity, which allows the city to maintain an array of international contacts and participate in many international forums as a non-sovereign actor (Tang 1993; Richard 1997). Hong Kong's status and recognition on the international stage defied simple categorization using traditional concepts from political science and international relations.

Such a political-cultural frontier approach is important for our understanding of the establishment of the Chinese University of Hong Kong, a major university in the territory. Specifically, the university was established through the merger of several colleges, which were founded by those exiled Confucianists and supported by the British colonial and the US governments for the purposes of defusing the tensions between the pro-Beijing and pro-Taipei 
camps and containing communist influence in Hong Kong and Asia (see Wong 2005; Chou 2010 for details). Duara (2016) points out that this observation about political and cultural ambiguity can also explain the situation in the early colonial era:

(Hong Kong) was an important contact zone between imperialism and nationalism where national and developmental ideas could encounter colonial and free-trade principles to generate hybrid and new practices beholden to neither political ideology. (p. 212)

This idea of melding British imperialism and Chinese nationalism was exemplified by the establishment of the University of Hong Kong, the leading university in the city. The university emerged as an imperialist project that aimed to institutionalize Western civilization in China and produce Anglicized ruling Chinese elites to support British colonial rule on the one hand. On the other hand, it responded to the desire of the Chinese, in both Hong Kong and Mainland China, for authentic Western education during the time. Importantly, according to Frederick Lugard, the then Hong Kong Governor and the founder of the university, one goal of the university was to "assist China to educate her sons without exposing them to long exile and the risk of denationalization" (cited in Law 2009, p. 74). Thus, Lugard decided that the university provided secular education to avoid uprooting the students from their own tradition, despite emphasizing Western superiority. Given the incorporation of the Chinese nationalistic consciousness and narrative in its establishment, the university is considered an embodiment of a blend of British colonialism and Chinese nationalism (see Law 2009 for details).

Postiglione's (2013) cosmopolitan model succinctly illustrates the relevance of the internationally shaped approach to HE development in post-handover Hong Kong. By investigating the development of the Hong Kong University of Science and Technology, an American-style research university which was established in the late colonial era and continued to grow rapidly after the handover, Postiglione argues that extensive international research collaboration and international recruitment are important factors for the rapid growth of the university. Based on this finding, he emphasizes that access to global knowledge networks is essential to Hong Kong HE's success and acknowledges the importance of the British colonial legacy, cultural inheritance of Chinese traditions, and Hong Kong's position as China's gateway. Admittedly, academics in Hong Kong have become more international since 1997 as more individuals with diverse backgrounds enter the system rather than those with a direct link to colonial Britain (i.e., institutional leaders and academics from diverse regions including Mainland China).

Lo (2016) further argues that the international and hybrid elements in Hong Kong's HE exist as a variant of Chineseness. In light of Tu's (1991) notion of "the periphery as the center," Lo suggests that such variants can serve as a frame of reference for building the subjectivity and worldview of Chinese societies. Extending the concept of the Chineseness frontier, he sees Hong Kong's HE system and its counterparts in other Chinese societies as unbounded Chinese cultural carriers and makers. The unbounded nature, which echoes the internationally shaped approach, refers to the situation where the cultural mixtures are nested in the global knowledge networks (Wang 2009). This conceptual understanding of Hong Kong's HE is consistent with arguments in favor of political ambiguity (Richard 1997) because the inter-referential awareness about building worldview exists only when the Chinese state appreciates or at least tolerates the cultural differences and the associated incongruities in a hybrid model (Lo 2020). 
In short, according to the internationally shaped approach, Hong Kong entrenches its internationalized legacy by naturally displaying a tendency of leaning toward both East and West (Shen 2010); thus, the essence of the hybrid and international elements of Hong Kong's HE is "glocal" (Chu 2011) or "glonacal" (Jaffee 2013) rather than national.

\section{Research methods}

The research informing this paper involves 16 semi-structured interviews with individuals at seven target universities selected through purposive sampling (Table 1). To explore universities' participation in the BRI and the GBA plan, we visited all major universities in Hong Kong to identify those who offered specific programs, initiatives, and projects that addressed the BRI or the GBA plan. We interviewed 12 leaders from these universities, including vice presidents, associate vice presidents, deans, associate deans, directors of international offices, and directors of their BRI- and GBA-themed research centers. The interviews explored institutional rationales for engaging with BRI and GBA, their experiences and perceptions at the institutional and individual levels, and future aspirations. Supplementing perspectives from university leaders are insights on frontline experience drawn from interviews with four faculty members who were strategically recruited by a major university for strengthening its engagement with the BRI in both research and teaching. All interviews were transcribed and analyzed for common themes, which were informed by the two theoretical approaches -nationally oriented and internationally shaped, as discussed earlier.

\section{Findings}

Our analysis of the interview data leads us to make three observations, which capture the participation and role of Hong Kong's universities in the Chinese grand strategies and as representation of Hong Kong as an exemplar of global connectivity.

Table 1 Participants in this study

\begin{tabular}{lll}
\hline Institution & Role & Participants \\
\hline University A & Director of Research Center & 1 \\
University B & Director of Research Center & 3 \\
& Associate Vice President ${ }^{2}$ & 1 \\
University C & Director of Research Center & 2 \\
& Associate Vice President ${ }^{2}$ & 1 \\
University D & Director of Research Center & 1 \\
University E & Director of Research Center & 1 \\
University F & Director of International Office & 1 \\
University G & Vice President & \\
& Faculty Member & 1 \\
\end{tabular}

Notes: 1. Some of these directors held executive positions, such as vice president, dean, and associate dean. 2 . These vice presidents and associate vice presidents oversaw the international affairs of the universities. 


\section{Universities' participation}

Major universities in Hong Kong intended to participate in the BRI and the GBA plan because they were aware of the importance of these two initiatives. Our interview data suggests that such an emphasis on the potential of the two initiatives for China's national development and global influence essentially explains the establishment and development of three BRI- and GBA-themed research centers. Their directors had the following responses:

Belt and Road is one of the major initiatives proposed by Mainland China. Hong Kong has returned to China, so I think that is the mindset behind. At least, we need to figure out what we can contribute. [The research center] was formed with good intentions of thinking how higher education in Hong Kong can help... Recently, Greater Bay Area might be even a more important research theme for our program or the whole [research center]. (UA1)

Belt and Road is the key platform of Chinese external engagement in the coming years. We've been keeping track and when the Hong Kong government announced this [BRIrelated] policy research grant scheme, we decided to put in a proposal. But, even before that we were starting to do some programs on Belt and Road because we thought it would be a big issue for China and emerging markets. (UE1)

Why we work on Belt and Road is because this is one of the major initiatives coming from the central government some years ago. Even though it is attracting a lot of controversy in many parts of the world, including China and Hong Kong, we share the idea that this is nonetheless an important idea for better or for worse. It has been consuming lots of resources. As an academic and as a stakeholder of the country, I think we cannot ignore it. (UB1)

A vice president at University $G$ further noted:

Belt and Road is a fantastic platform for not just higher education, but also regional development for both Mainland China as well as the countries around the regions you know, Central Asia extending to East Africa all the way down to Central Europe. So clearly, I think this is something that our university takes very seriously. It's actually written in our strategic document for the next 10 years. This is part of our strategy. (UG1)

This awareness of the importance of the national projects had turned into a recruitment strategy with which University $G$ hired four faculty members for strengthening its teaching and research on the BRI. One of these faculty members explained that there was such a recruitment strategy because "University A has been more ahead of the game in terms of hiring for Belt and Road, so University G wanted to compete" (UG3). Another faculty member who was hired through this strategic recruitment scheme added that the BRI not only drew attention from her current institution, but also from her former employer:

I left my position in University F, which is also promoting the BRI. My former colleagues are also working on the BRI, so I am more or less influenced by them... 
[My research project] developed from two years before, so you can actually see that this idea is already born before I came to University G. (UG4)

These responses demonstrate the justifications for embracing the BRI- as well as GBA-themed initiatives among Hong Kong universities. As indicated by Kirby and van der Wende (2019), the HE sectors in different parts of the world have recognized the rise of China and its significant implications for the geopolitical transformation of HE. Thus, while leading Chinese universities were encouraged and funded to contribute to the BRI, the initiative also received positive responses from European universities. This observation about the extra-territorial influence of the BRI on HE is reiterated by Peters (2020) who notes that the BRI "represents a new stage of globalization that builds connectivity with Eurasia and can reconfigure global HE working collaboratively with universities of 130 countries, and new partnerships with Russia and EU" (p. 589). Echoing this "going global" strategy, the GBA plan aims to transform China into "an innovation nation" and "a major knowledge creator and partner, for research systems globally" (Mok et al. 2020, p. 195) through the processes of regional integration, technological innovation, and internationalization, in which HE plays a significant role (Xie et al. 2021).

Our interview data suggests similar findings on the responses from the HE sector in Hong Kong. Senior managers often spoke about their awareness of how the national initiatives could provide funding and collaboration opportunities for universities and become crucial to the future of Hong Kong and its $\mathrm{HE}$ (UB2; UC1; UG1). One of them highlighted the significance of removing restrictions on Hong Kong academics' access to research funding from the Chinese central government. He believed that this policy would not only facilitate research collaborations among Hong Kong and Mainland researchers, but would also allow Hong Kong universities to actively participate in national science and technology development in the Mainland (UC1). These narratives reveal how the two national initiatives may have repositioned Hong Kong's universities. As Postiglione (2018) notes, while the BRI "will deepen educational and academic cooperation with the Belt and Road countries, especially those in South and Southeast Asia", the GBA plan "will give a role to universities in making the region competitive with the high tech centers in San Francisco, Tokyo and New York" (p. 7). Recent research also indicates that universities in Hong Kong aspire to take a role in the development of the city's technological innovation through the GBA plan (Kang and Jiang 2020; Lo and Tang 2020; Tang 2020). These aspirations resonate with the narrative presented in our interview data. Furthermore, the narratives identify engagement with Chinese national development as a future direction in $\mathrm{HE}$ in Hong Kong, a point to which we will return later.

\section{Cultural broker}

Hong Kong's unique role as an intermediary between Chinese civilization and the world at large is well documented. Significantly, most participants in our study shared this perspective about a tendency of leaning toward both China and the Western world as the niche for Hong Kong's HE. For example, a director of a research center at University A noted:

That's why we need to search for our own niche - something that is not replaceable at least at this stage. It could be an internationalized mindset and most of the multicultural mindset that we have. For example, many of our experts on China studies at University A are Western educated and many of them are westerners. If someone wants to have a 
person in the team that can reach both sides... If you go directly to China, the good thing is [that] you already have the so-called cultural broker on your team. Otherwise, it's going to be hard, because it takes time to get trust from the Mainland... How could you get their trust and cooperation? (UA1)

This excerpt resonates with Postiglione's (2013) analysis of Hong Kong HE's success, in which he emphasized the city's ability to attract a critical mass of "overseas networked Chinese scholars" who have strong global connectivity on the one hand and "emotional attachment to their cultural heritage and intense commitment to China's development" on the other hand (p. 362). This combination of global and national features is construed as "a niche" in the field of science and technology for Hong Kong academics.

In contrast, another director at University C observed that his collaborators from Southeast Asia lacked trust in the legal and financial systems in Mainland China but had more trust in those in Hong Kong because of the bilingual and more international environment of the city (UC2). Having trusting relationships with both Chinese and foreign parties, the director of the international office at University F, which was active in a BRI-themed university alliance, elaborated on Hong Kong's intermediary role, thereby articulating the notion of leaning toward both sides:

They [representatives of a foreign university] had already approached [universities in] Shanghai before contacting me. They just came back from Shanghai. But, in their collaboration [with the Chinese partners], they faced some problems. They wanted some third-party advice. I think sharing our experience and advice is one of the goals of Hong Kong. (UF1)

She further explained that as University F has several centers in the Chinese Mainland, it could effectively help foreign universities establish collaborations with Chinese institutions by building tripartite relationships:

We line them up... If they [foreign universities] want to go there [the Chinese Mainland] through us, we form some tripartite collaborations. If they have already had a partner and we have our own, we bring the four parties together. We facilitate tripartite partnership, which is more interesting because culturally Hong Kong universities are quite close to Western culture but geographically and linguistically, we're close to the Mainland. So, we can have our role to play. (UF1)

An associate vice president who oversaw the international affairs of University B commented on the degree of internationalization of Chinese universities, which offered an explanation for the tripartite partnership:

Financially, they [universities in China] are probably even better off than us [universities in Hong Kong]. But, at the same time, given the culture, the languages, and the way universities are being managed, I think they are still far behind what really means to [be international]... So, I think if the central government is really interested in promoting internationalization, especially making this BRI actually happen at institutions, there're a lot of collaborations they should have with us. (UB2) 
These responses provide some evidence of the relevance of the globally shaped approach to the development of HE in Hong Kong, as they illustrate how the city's cultural proximity to both China and the West is significant in facilitating academic collaboration. These responses from the HE sector also confirm the significance of the concept of "Hong Kong as a super-connecter" as proposed by HKSAR policymakers (BRO, 2017).

However, it is worth noting that a vice president at University $\mathrm{C}$ expressed skepticism toward Hong Kong's mediating role in response to questions about the BRI:

[The idea of Hong Kong as a super-connecter is] at least 50\% nonsense. Ask us how much language we know about Kazakhstan? Can I expect that I just walk into a shopping mall or shop and I can finish the transaction in English? No. Can I speak Kazakh? No. Never heard of it. Can I speak Russian? Probably, two words. So, it is they connecting us, not we connecting them. (UC3)

When asked about whether his foreign partners sought his help in establishing partnership with China, he stated:

It's no longer that significant. Most of them can fly directly to Shanghai and Beijing. They still appreciate our understanding of China, being more sophisticated and more complex than they understand it. We are able to really go down to the local community, but that's something that they do now. Honestly, I have talked to presidents from universities in the UK because every one or two years they had a group visiting Mainland China, and then they would stop in Hong Kong. They do like someone from Hong Kong to give them some sort of briefing or overview about connection with China. They still find that we know a lot more than they do. But, in fact, China would welcome someone just directly coming from a foreign country. So, we don't really have a very strong role. (UC3)

The director of a BRI-themed research center at University B also noted that the international reputation and networks of his Chinese partner university, which is a top university in the Mainland, are much stronger than those of his university:

It [his Chinese partner university] is much more reputable. It has huge US connections. All the members of its advisory board are so impressive. We have impressive people in our advisory board too, but not as impressive as they are. We are not even close. (UB3)

We see these excerpts as preliminary evidence illustrating a possible shift in which Hong Kong's HE sector plays a diminishing role as a gateway within the context of a globalizing China. Further, as Lo (2020) argues, while "being globally networked and outward-looking is considered a key factor that establishes and maintains Hong Kong's status as a gateway in higher education," "an inward-looking culture seems to have emerged in the city" (pp. 1364-1365). Such an inward mentality is shown by the fact that Hong Kong has been increasingly reliant on Mainland China. Thus, there is concern that integration with the Mainland as promoted by the GBA plan further accelerates the shift toward a national narrative. We elaborate on this shift in the following sections. 


\section{Agency and autonomy}

As previously noted, academic literature offers the nationally oriented approach, which foregrounds China's national development when explaining Hong Kong's global position and its HE's engagement with the BRI and the GBA plan. This theoretical orientation is also evident in Hong Kong's inclusion in China's national development plan since the 11th Five-Year Plan issued in 2006. HKSAR's policy addresses also recognize Hong Kong's international profile as its unique advantages for the purposes of serving the country's needs and facilitating the city's integration into the overall national development ( $\operatorname{Lam} 2017,2020)$. In the realm of HE, the agenda for integration into national development rationalizes the collaborative projects, such as branch campuses and cross-border research funding schemes, between Hong Kong and Chinese universities in the GBA (Lo and Tang 2020).

In our research, the emphasis on national development was particularly relevant to explain the case of University $\mathrm{G}$ which employed a top-down decision to hire a few faculty members for facilitating the university's involvement in the BRI (UG3). When explaining the rationale for the participation of his university in the national initiatives, an associate vice president at University B also suggested that "the government's gesture is really important" in guiding the direction of development (UB2). However, most of our participants stressed that their universities adopted a decentralized model, in which their participation in the national projects was primarily driven by individuals' willingness and interests. For example, a director of a research center at University B explained:

The research team is $100 \%$ faculty driven. The senior management needs to come with some judgments one way or the other and obviously it is no secret that our former chairman [of the university's council] is very supportive of the [BRI]. But our project has nothing to do with his keenness... Basically it is all bottom up. (UB1)

Similarly, despite highlighting his collaboration with a Chinese central ministry during the interview, a dean who was also the director of a BRI-themed research center at University B stressed that "all the research and educational programs were based on rigorous academic considerations." He stated:

We're not trying to respond to the government call. It [his involvement in the BRIrelated projects] is from a university angle, from our research angle... We see this [the $\mathrm{BRI}$ as a big, major economic activity, which is proposed or sponsored by the Chinese government. (UB3)

His associate dean and co-director added:

This economic event [the BRI] is just happening next to us as an academic institution. If we don't watch it, who's going to watch it? If we don't study it, who's going to study it? Because this thing is just next to us. We just see there's an opportunity for research... And, probably we can contribute with our thorough, rigorous academic study or probably can help that initiative from our academic angle. We are not [responding to] the government. (UB4) 
The director of the international office at University $\mathrm{F}$ also conceded that her university actively participated in the BRI-related activities mainly because of the strong personal relationship between the senior management of her university and that of the Chinese collaborators (UF1). A director of a research center at University A further noted that she could not force her colleagues to be involved in the projects of her center, as "every academic has [his/her] own research interests" (UA1). The faculty members who were hired for strengthening University G's engagement with the BRI also mentioned that they were autonomous to decide what to teach and research, though they were expected to deliver some BRI-related teaching and research activities (UG2-UG5). These responses reveal that Hong Kong academics retain autonomy to decide whether and how they participate in the national projects despite the rhetoric of national development at the policy level and among senior institutional leaders.

At the same time, crucial to universities' strategic engagement with Chinese national development is Hong Kong's tense social atmosphere, in which there are anxieties about the intensification of integration with the Mainland. A director at University B, whose research center facilitates BRI collaborations between professional and academic sectors in Hong Kong and those in Mainland China, elaborated the rationale for her project, uncovering a skeptical perspective on the BRI:

There is popular skepticism towards Belt and Road [in Hong Kong]. If there were [such] skepticism in the professional sectors... This is precisely why we need this project. (UB1)

She situated this skepticism in the wider political context in the territory:

We want to understand the professional sectors' attitude if they are skeptical, then we have to talk to them and understand their skepticism... This is not something peculiar to Belt and Road. If there is anything from the Mainland, immediately we [people in Hong Kong] have a cloud [suspicion]. (UB1)

We argue that this skepticism reveals the fundamental conflict between the internationally shaped and nationally oriented approaches. According to the internationally shaped approach, the international profile of Hong Kong (Duara 2016; Chan 2019) as well as that of its HE sector (Wong 2005; Chou 2010) is a by-product of geopolitics during the Cold War and colonial era as Hong Kong experienced dramatic transformations. This profile radiates cultural hybridity as well as political ambiguity. Alternatively, the nationally oriented approach was proposed to respond to the changing political economic situation after the handover. This approach has led to growing anxieties over "Mainlandization," which refers to "political and legal processes in which the HKSAR has demonstrated the practices of Mainland China" (Lo 2008, p. 42). Politically, these anxieties, which are essentially connected with the rise of localism in Hong Kong (Kwong 2018), are portrayed by political tensions in the society (Dupré 2020) as well as discontent on university campuses (Law 2019). Nonetheless, it is important to note that, from the internationally shaped perspective, a theoretical framing focusing on historical and cultural contexts, emphasizing integration with Mainland China (or Mainlandization) implies abandonment of political ambiguity, which not only undermines the particularity of Hong Kong's system but also weakens its cosmopolitan status in the near future. 


\section{Discussion and conclusion}

Scholarly accounts of the global profile of Hong Kong's HE typically focus on its access to international knowledge networks. For example, Postiglione's (2013) thesis of anchoring globalization highlights the importance of internationalism, which is characterized by international recruitment and research collaborations, in shaping Hong Kong's academic model. Recent research then presents growing concern over the impacts of the growing integration with the Chinese Mainland on the HE development in the city (e.g., Kang and Jiang 2020; Lo and Tang 2020; Tang 2020). However, these studies insufficiently address the interplay between the access to global networks and the national ambit of Mainland China for Hong Kong's HE development. Thus, this paper has addressed the interplay through an examination of Hong Kong universities' participation in two major national policy initiatives in China.

This paper shows university leaders and academics in Hong Kong as fully cognizant of the importance of the Chinese national agenda to HE development in the territory. This awareness rationalizes most of their participation in the BRI and GBA plan at the institutional and individual levels. However, despite an overt engagement with national development at both the policy and institutional levels, the universities in our study adopted a decentralized model in which individual academics were free to decide whether and how to participate in the related projects. With this decentralized model, policy agendas and institutional logics are mediated by individual motivations and agency. This finding enriches our understanding of the multilevel determinants of rationales for engagement with China's grand strategies (cf. Lee et al. 2020). It also affirms institutional autonomy and individual academic freedom as cornerstones of Hong Kong's HE system.

Furthermore, our findings affirm the significance of international linkages and the cultural proximity to both China and the Western world in constructing Hong Kong as a cultural broker and an exemplar of internationalism in HE. This cultural proximity, as articulated by university leaders in our study, is important because it verifies the continuing relevance of leaning toward both East and West in post-handover Hong Kong. It also sustains the city's role as a connector, even though China has substantially opened up to the world to provide direct access.

However, as we have noted, this cultural proximity emerged within the colonial sociopolitical context in which political ambiguity was permitted and even upheld by Britain and the international community. There is now growing concern that the prevalence of nationalist ideologies, which appeared in many decolonization movements worldwide, may curtail Hong Kong's cosmopolitan orientation (Duara 2016). Our findings raise questions about the viability of policy initiatives that require Hong Kong to integrate closely with China's national development agenda. Significantly, this skepticism toward a national development agenda echoes the rise of localism and anti-Mainland sentiments in Hong Kong over the last decade as social movements expose political discontent. Ultimately, to suppress the social unrest, the Chinese central government introduced a National Security Law in Hong Kong in 2020.

Accentuating national security and interests characterizes the inherent tensions between "becoming Chinese" and "remaining global" in the evolution of the international status of Hong Kong. Admittedly, state authority is intrinsic to the Chinese development model, which views universities as critical institutions for national development. National needs and interests have priority over other considerations (Zha 2011). Consequently, there is a highly centralized system, which emphasizes the party-state's ideological control over academia, particularly humanities and social sciences, and runs against Western norms and ideologies, in Mainland China (Xu 2021). Thus, melding the internationally shaped and nationally oriented approaches 
is challenging if not impossible. In other words, staying politically ambiguous, which is emphasized in the internationally shaped approach, is incongruent to the ethos of a national development agenda. To explain the root cause of the tensions, Yang (2020) argues that Hong Kong has neglected the significance of the Chinese political culture, which stresses a hierarchical relationship among social actors, in the development of its HE governance. He notes that "the Hong Kong higher education system has shown little respect for traditional culture. Institutionally the system only accepts Western rules and behavior" (p. 231). Marginson (2021) also points out that the differences between the political cultures in Mainland China and Hong Kong lead to "a head-on collision between the Western and Sinic "Idea of a University"' (p. 5). In this context, Jiang and Wang (2020) advocates that strengthening the government's monitoring of HE by reforming university governance and promoting patriotic education is necessary for Hong Kong HE's further integration into the Chinese national development.

Emphasizing national interests also explains the effects of the ongoing Sino-American rivalry on HE. Indeed, the political tensions between the two countries have hindered academic collaborations and exchanges between China (including Hong Kong) and the USA. Moreover, Hong Kong seems to have become a battleground for the deteriorating relationship between the two countries. As an example, the USA placed sanctions on top Hong Kong officials and revoked the city's special status under US law. In response to these punitive actions, Hong Kong's leader reiterated the importance of integration into Chinese national development and the "unlimited opportunities" provided by the BRI and GBA plan (Lam 2020, para. 38). These developments demonstrate the impact of geopolitical flux on HE as well as the specter of international intervention in further polarizing politics in Hong Kong - a warning that some expressed at the dawn of the post-colonial era (Richard 1997). The prospect of Hong Kong transforming from an East-West cultural gateway to a Sino-American political crucible is difficult to ignore.

We conducted our field research before the protests in 2019-2020; therefore, we cannot assess the impacts of the political and social unrest. Instead, the value of this study is to bring the issue of global positioning and national orientation in Hong Kong into a theoretical dialogue and reflect on possible outcomes. According to the internationally shaped approach, the global status of the territory primarily lies in the conditions of political ambiguity and cultural proximity. Yet, the current geopolitical situation, in which political ambiguity is rapidly fading, poses a serious threat to Hong Kong's trajectory in internationalism and historical role as a cultural gateway. One possible outcome within this scenario would be for Hong Kong HE to retain its renowned institutional autonomy, academic freedom, and remarkable international engagement, while Hong Kong society integrates closely with Mainland China. While this outcome maintains political ambiguity within the HE sector, it conjures up an unfathomable parallel universe whereby universities enjoy the privileges of intellectual pursuits as distinct from societal norms. However, recent incidents (e.g., universities cutting ties with their pro-localism student unions) have undermined the possibility of this outcome.

In contrast, the nationally oriented approach, which emphasizes the primacy of national development among competing urban centers in China, assumes that Hong Kong's international engagement is in consonance with China's thriving national development and going global strategy. Thus, an optimistic scenario is that Hong Kong, as a springboard to opportunities in the Chinese Mainland, will remain pivotal to China's continual growth and global outreach (e.g., the BRI). In this scenario, the changing political conditions will not substantially weaken Hong Kong's global connectivity. In this context, a deeper integration into the 
national development will enable the development of a successful HE sub-national region within the GBA framework, given the mutual complementation among Hong Kong and its neighboring cities in the Mainland (Wang et al. 2021). Nevertheless, a pessimistic view of the development is that the rapidly changing political situations will cause a deteriorating global profile of Hong Kong. Thus, in the context of a globalizing China, the deeper integration will only accelerate the process in which other Chinese cities like Shenzhen and Shanghai eclipse Hong Kong's position as a global city.

Understanding the link between geopolitics and academia, we see Hong Kong as an illustrative example of international engagements in the face of dramatic changes in national policymaking and global posturing. Thus, following the anticipation that China's grand strategies will reshape the global geopolitical landscape and the worldwide field of $\mathrm{HE}$ (Peters 2020; van der Wende et al. 2020), we suggest that these different versions of the future of Hong Kong draw further debates and attention to research on HE.

Funding This study was funded by the Education University of Hong Kong (Project No. RG96/16-17R).

Open Access This article is licensed under a Creative Commons Attribution 4.0 International License, which permits use, sharing, adaptation, distribution and reproduction in any medium or format, as long as you give appropriate credit to the original author(s) and the source, provide a link to the Creative Commons licence, and indicate if changes were made. The images or other third party material in this article are included in the article's Creative Commons licence, unless indicated otherwise in a credit line to the material. If material is not included in the article's Creative Commons licence and your intended use is not permitted by statutory regulation or exceeds the permitted use, you will need to obtain permission directly from the copyright holder. To view a copy of this licence, visit http://creativecommons.org/licenses/by/4.0/.

\section{References}

Belt and Road Office (BRO). (2017). https://www.beltandroad.gov.hk

Chan, K. K. L. (2019). Hong Kong in the world: Continuities and changes. Asian Education and Development Studies, 8(2), 197-207.

Chiu, S., \& Lui, T.-L. (2009). Hong Kong: Becoming a Chinese global city. Routledge.

Chou, G. A.-L. (2010). Cultural education as containment of communism: The ambivalent position of American NGOs in Hong Kong in the 1950s. Journal of Cold War Studies, 12(2), 3-28.

Chu, S. Y.-W. (2011). Brand Hong Kong: Asia's world city as method? Visual Anthropology, 24(1-2), 46-58.

Constitutional and Mainland Affairs Bureau (CMAB). (2018). https:/www.bayarea.gov.hk/en/home/index.html.

Duara, P. (2016). Hong Kong as a global frontier: Interface of China, Asia, and the World. In P. Roberts \& J. M. Carroll (Eds.), Hong Kong in the Cold War (pp. 211-230). Hong Kong University Press.

Dupré, J. F. (2020). Making Hong Kong Chinese: State nationalism and its blowbacks in a recalcitrant City. Nationalism and Ethnic Politics, 26(1), 8-26.

Han, Z., \& Paul, T. V. (2020). China's rise and balance of power politics. The Chinese Journal of International Politics, 13(1), 1-26.

Hui, E. C. M., Li, X., Chen, T., \& Lang, W. (2020). Deciphering the spatial structure of China's megacity region: A new bay area-The Guangdong-Hong Kong-Macao Greater Bay Area in the making. Cities, 105, 1021683 .

Jaffee, D. (2013). Building general education with Hong Kong characteristics. International Education, 42(2), 41-59.

Jiang, K., \& Wang, T. (2020). Integrating into the overall context of national development: An analysis of the prospects for the development of the higher education of Hong Kong, China. Educational Research, 491 (12), 86-97 [in Chinese]. 
Kang, Y., \& Jiang, J. (2020). Revisiting the innovation systems of cross-border cities: The role of higher education institution and cross-boundary cooperation in Hong Kong and Shenzhen. Journal of Higher Education Policy and Management, 42(2), 213-229.

Kirby, W., \& van der Wende, M. (2019). The New Silk Road: Implications for higher education in China and the West? Cambridge Journal of Regions. Economy and Society, 12(1), 127-144.

Knight, J. (2013). Education hubs: International, regional and local dimensions of scale and scope. Comparative Education, 49(3), 374-387.

Kwong, Y.-H. (2018). Political repression in a sub-national hybrid regime: The PRC's governing strategies in Hong Kong. Contemporary Politics, 24(4), 361-378.

Lam, C. (2017). 2017 policy address: We connect for hope and happiness. Government Printer.

Lam, C. (2020). 2020 policy address: Striving ahead with renewed perseverance. Government Printer.

Law, W. S. (2009). Collaborative colonial power: The making of the Hong Kong Chinese. Hong Kong University Press.

Law, W. W. (2019). Politics, managerialism and university governance: Lessons from Hong Kong under China's rule since 1997. Springer.

Lee, J. T. (2014). Education hubs and talent development: Policymaking and implementation challenges. Higher Education, 68(6), 807-823.

Lee, J. T., Lo, W. Y. W. \& Abdrasheva, D. (2020). Institutional logic meets global imagining: Kazakhstan's engagement with China's Belt and Road Initiative. Higher Education, advance online publication, 1-17.

Lo, S. S.-H. (2008). The dynamics of Beijing-Hong Kong relations: A model for Taiwan? Hong Kong University Press.

Lo, W. Y. W. (2015). Revisiting the notion of Hong Kong as a regional education hub. Higher Education Policy, $28(1), 55-68$.

Lo, W. Y. W. (2016). The concept of Greater China in higher education: Adoptions, dynamics and implications. Comparative Education, 52(1), 26-43.

Lo, W. Y. W. (2020). A year of change for Hong Kong: From east-meets-west to east-clashes-with-West. Higher Education Research and Development, 39(7), 1362-1366.

Lo, W. Y. W., \& Tang, H. H. H. (2020). Chasing phantoms? Innovation policy, higher education and the pursuit of a knowledge economy in Hong Kong. Journal of Higher Education Policy and Management, 42(2), 178193.

Marginson, S. (2021). One country, two political cultures: What way forward for Hong Kong's universities? International Journal of Educational Development, 84(102426), 1-6.

Mok, K. H., Welch, A., \& Kang, Y. (2020). Government innovation policy and higher education: The case of Shenzhen, China. Journal of Higher Education Policy and Management, 42(2), 194-212.

Peters, M. (2020). China's Belt and Road Initiative: Reshaping global higher education. Educational Philosophy and Theory, 52(6), 586-592.

Postiglione, G. A. (2013). Anchoring globalization in Hong Kong's research universities: Network agents, institutional arrangements, and brain circulation. Studies in Higher Education, 38(3), 345-366.

Postiglione, G. A. (2018). Hong Kong's higher education-20 years after handover. Higher Education in Southeast Asia and Beyond, 3, 5-7.

Ren, S., Li, X., \& Chen, T. (2020). Retrospect and prospect of Guangdong, Hong Kong, and Macao's economic relations since reform and opening-up. China City Planning Review, 29(2), 46-55.

Richard, K. (1997). A high degree of ambiguity: Hong Kong as an international actor after 1997. The Pacific Review, 10(1), 84-103.

Shen, S. (2010). Re-branding without re-developing: Constraints of Hong Kong's "Asia's World City" brand (1997-2007). The Pacific Review, 23(2), 203-224.

State Council. (2015). Vision and actions on jointly building silk road economic belt and 21st-century maritime silk road. National Development and Reform Commission.

Tang, T. H. J. (1993). Hong Kong's international status. Pacific Review, 6(3), 205-215.

Tang, H.-H. H. (2020). The strategic role of world-class universities in regional innovation system: China's Greater Bay Area and Hong Kong's academic profession. Asian Education and Development Studies, advance online publication, 1-16.

Tu, W.-M. (1991). Cultural China: The periphery as the center. Daedalus, 120(2), 1-31.

University Grants Committee (UGC). (2010). Aspirations for the higher education system in Hong Kong Report of the University Grants Committee. Universities Grants Committee.

van der Wende, M., Kirby, W. C., Liu, N. C., \& Marginson, S. (Eds.). (2020). China and Europe on the new silk road: Connecting universities across Eurasia. Oxford University Press.

Wang, G.-W. (2009). Chinese history paradigms. Asian Ethnicity, 10(3), 201-216.

Wang, J., Chandra, K., Du, C., Ding, W., \& Wu, X. (2021). Assessing the potential of cross-border regional innovation Systems: A case study of the Hong Kong -Shenzhen region. Technology in Society, 65, 1-11. 
Wong, T.-H. (2005). Comparing state hegemonies: Chinese universities in postwar Singapore and Hong Kong. British Journal of Sociology of Education, 26(2), 199-218.

Xie, Y., Zhang, C., \& Lai, Q. (2014). China's rise as a major contributor to science and technology. Proceedings of the National Academy of Sciences of the United States of America, 111(26), 9437-9442.

Xie, A., Postiglione, G. A., \& Huang, Q. (2021). The Greater Bay Area (GBA) development strategy and its relevance to higher education. ECNU Review of Education, 4(1), 210-221.

$\mathrm{Xu}, \mathrm{X}$. (2021). A policy trajectory analysis of the internationalisation of Chinese humanities and social sciences research (1978-2020). International Journal of Educational Development, 84(102425), 1-10.

Yang, R. (2020). Political culture and higher education governance in Chinese Societies: Some reflections. Frontiers of Education in China, 15(2), 187-221.

Zha, Q. (2011). Is there an emerging Chinese model of the university? In H. Hayhoe, J. Li, J. Lin, \& Q. Zha (Eds.), Portraits of 21st century Chinese universities: In the move to mass higher education (pp. 451-471). Comparative Education Research Centre, The University of Hong Kong and Springer.

Publisher's note Springer Nature remains neutral with regard to jurisdictional claims in published maps and institutional affiliations. 